\title{
Biochemical evaluation of antibacterial activity of short and medium chain fatty acids in broiler
}

\author{
Abdel Maksoud Hussein ${ }^{1, *}$ Mahfouz Khaid Mohamed ${ }^{1}$, Afaf Abd Elmagid Desoky ${ }^{1}$, Yomna Hegazy ${ }^{1}$ and \\ Ahmed Fotouh 2 \\ ${ }^{1}$ Biochemistry and Clinical Biochemistry Department, Benha University, Egypt. \\ ${ }^{2}$ Department of Parasitology and Animal Diseases, National Research Center, Egypt. \\ Publication history: Received on 14 October 2019; revised on 09 November 2019; accepted on 13 November 2019
}

Article DOI: https://doi.org/10.30574/gscarr.2019.1.1.0007

\begin{abstract}
The objective of the present study was to evaluate the antimicrobial effect of short and medium fatty acid chain. Total number of 2000 Cobb broiler chicks (mixed sexes) were commercially purchased from EL Dakahlia poultry company that were $1 \mathrm{~d}$ old were reared up to $40 \mathrm{~d}$ of age. Corn and soybean meal based starter and grower diet were supplemented. Chicken were randomly divided in to two main group, $1^{\text {st }}$ group act as normal control, $2^{\text {nd }}$ group was add C12 ( mixed short and medium fatty acid) in drinking water for 3 day each 8 day at 11, 22 and 33 days age. Blood sample were collected before and after taking C12 treatment for biochemical examination. Supplementation of C12 caused decrease in serum level of AST, ALT, glucose, cholesterol, triglyceride, and pro-inflammatory cytokines as IL-6, increase HDL and total protein. Evaluation of antimicrobial activity of C12.
\end{abstract}

Keywords: Organic acids; Short chain fatty acid; Medium chain fatty acid; Antibacterial activity

\section{Introduction}

Food producing animals are an important reservoir of some of serious pathogens. Therefore, there is increasing concern about controlling the spread of bacterial pathogens in animal husbandry. "Pathogen reduction" strategies in the food chain can also result in significant economic gain. Organic acids are widely distributed in nature as normal constituents of plants or animal tissues. They are also formed through microbial fermentation of carbohydrates predominantly in the caeca of poultry [1]. Supplementation of organic acids in the diet increased lactic acid bacteria (LAB) counts in the ileum and cecum of broiler chickens. Numerous parameters oversee the survival and development of microorganisms. All microorganisms have minimum, maximum and optimum PH level for growth and altering the hydrogen ion concentration influences the growth or inhibition of an organism. One powerful method for limiting growth of bacteria is increase the acidity. This action tends to be micro biostatic rather than microbiocidal. In terms of performance, feeding organic acids resulted in improved body weight gains and feed conversion ratio [2]. Antimicrobial property of acids has been suggested to play a crucial role in controlling the population of pathogenic bacteria in the gut of birds [3].

Organic acids can also be used as feed or drinking water additives [4]. A wide range of organic acids are used as drinking water supplements or as feed additives (acidifiers). The mechanism of action of organic acids decreasing the $\mathrm{pH}$ of drinking water and reducing the buffering capacity of the feed with subsequent effect on the physiology of the crop and proventriculus [5].

Organic acids to reduce pH in the lower gut are highly desirable, because the lower gut is colonized by many anaerobic opportunistic pathogens. Reduction of the intestinal $\mathrm{pH}$ might depress the growth of pathogenic bacteria, reduce

\footnotetext{
${ }^{*}$ Corresponding author

E-mail address: hm2243049@gmail.com
} 
subclinical infections, and support the proliferation and growth of beneficial bacteria [6]. Fatty acids one group of chemicals found in nature and considered to have little or no toxicity is fatty acids and their corresponding esters. Fatty acids are carboxylic acids, regularly with a long aliphatic tail that may be either saturated or unsaturated. The antimicrobial effects of fatty acids have been well documented [7]. The bactericidal activity of lipids depends on their nature, particularly chain length, and on the bacterial strain involved. The antimicrobial effect varies with the length of the acid chain and its degree of saturation [8]. The chain lengths of fatty acids that were found to be most effective were C12 (saturated), C16:1 (unsaturated) and C18:2 (polyunsaturated). In addition, the chain length, the degree and type of unsaturation as well as the geometric isomerism are important determinants of the biocidal activity of a fatty acid. They are found in animal and vegetable fats and oils and have the general formula $\mathrm{CnH} 2 \mathrm{n}+\mathrm{lCOOH}$. Fatty acids are classified based on the number of carbons (C) present in the chain. Short chain fatty acids are usually 2-6 C in length (important in ruminant nutrition, i.e. propionate, butyrate, and acetate). Medium chain fatty acids are usually 8 To $12 \mathrm{C}$ in length, e.g. lauric acid. Long chain even number fatty acids are usually 14 to $20 \mathrm{C}$ and include palmitic, stearic, EPA and AA. Short-chain fatty acids (SCFAs) are saturated aliphatic organic acids that consist of one to six carbons, of which acetate (C2), propionate (C3), and butyrate (C4) are the most abundant (>95\%). The SCFA are primarily produced by microbial fermentation of diet-resistant carbohydrates and fiber in the colon, particularly butyrate in the hindgut [9].

The SCFA are the major fuels of colonocytes and provide 60-70\% of energy requirement for colonocytes. SCFA are essential for maintaining the normal metabolism of colon mucosa, regulating colonocyte growth and proliferation [10]. They have been shown to play an important role on improving intestinal heath and limiting intestinal inflammation. Short-chain organic acids have been widely used for the control of pathogenic bacteria.

Fatty acids with aliphatic tails of six to twelve carbon atoms are called medium-chain fatty acids (MCFA), which occur naturally in milk fat and various feed materials, especially coconut, palm oils and Cuphea seed oils [10]. MCFA and MCT have specific nutritional and metabolic effects, including rapid digestion, passive absorption and obligatory oxidation, making them particularly interesting for the nutrition of young animals. MCFA can be utilized directly by the enterocytes for energy production and thereby help to support the integrity of the intestine. [8].

The MCFA inhibits the production of lipases by the bacteria as lipases are needed to allow the bacteria to attach to the intestinal wall, this process will be prohibited and the bacteria will be removed [11].

Organic acids are weak acids and powerful tool in maintaining the health of the gastrointestinal tract (GIT) in poultry which improving the performance [12] Modification of gastrointestinal micro biota reduced colonization of the animals with pathogenic microorganisms, which can have a big influence on intestinal wall structure [13]. Therefore, the objective of the present study was to evaluate the antimicrobial effect of short and medium fatty acid chain.

\section{Material and methods}

\subsection{Chicken and experimental design}

A total of 2000 Cubb broiler chicks were commercially purchased from EL Dakahlia poultry company. The experiment lasted for 40 days. The initial brooding temperature was $33^{\circ} \mathrm{C}$ in the first week of age and reduced gradually $2^{\circ} \mathrm{C}$ per week until reaching about $20{ }^{\circ} \mathrm{C}$ at the end of experiment. The birds were kept under conventional conditions for vaccination, temperature, ventilation, and lighting based on Cobb catalogue, the chicks were provided with water soluble vitamins and electrolytes were added to the drinking water for 10 days according to ethical approval committee in Benha University. Before the beginning of the experiment, chicks were randomly divided in to main groups, 1 st group normal control group, 2nd group received C12 (short and medium fatty acid) country of origin: Netherlands, distributed by (Abo El-naga Trading Company) in drinking water. Supplementation of short and medium chain fatty acids to normal poultry with 3 doses at 11, 22 and 33 days age. During the experiment, the birds were fed on a starter diet for 14 days of age after that chicks were fed on grower diet which was given till the $28^{\text {th }}$ day of age then chicks were fed on finisher diet till the end of experiment. The diets were calculated to meet or exceed the nutrient requirements for broiler chickens recommended by NRC for poultry (1994).

\subsection{Blood samples}

Blood samples were collected before and after receiving C12 3times at 8, 19 and 30 days of age each time for 3days. Samples of blood were taken from the neck vein birds and then collected in blood clean sample tubes. The samples were centrifuged at $3.000 \mathrm{rpm}$ for 15 minutes for separating the serum. Part of serum samples were used for measuring the following biochemical parameters. 
(AST and ALT) was performed according to [14]. Total protein concentration according to [15]. Total cholesterol, serum triacylglycerol according to the method described by [16]. Serum HDL-C concentration was determined according to [17]. Serum LDL-C was calculated using the formula described by [18]. Serum Total protein concentration was determined according to the method described by [15] Serum glucose level was determined according to method described by [19]

The residual amounts of the sera were kept in deep freezer at -20 c for determination of Interleukins.

\subsection{Histopathological examination}

Tissue specimens were taken from intestine of authorized birds of control and test bird. These specimens were preserved in 10\% buffered neutral formalin. After proper fixation, the specimens were dehydrated in ascending grades of ethyl alcohol, then cleared in xylol and embedded in paraffin. Thin tissue sections of about 5 microns in thickness were prepared and stained with hematoxylin and eosin stain for general microscopic examination according to [20].

\subsection{Evaluation of antimicrobial activity}

Inhibition of microbial growth can be detected using a variety of methods, including direct microscopic counts, absorbance, assays that incorporate a colorimetric and fluorometric growth indicator, bioluminescence assays, turbidity, dry weight, and zones of inhibition.

An alternative measure of susceptibility is to determine the Minimum Inhibitory Concentration (MIC) and the Minimum Bactericidal Concentration (MBC) of an antimicrobial. A series of broths are mixed with serially diluted antimicrobial solutions and a standard inoculum is applied. After an overnight incubation, the MIC is the lowest concentration of an antimicrobial that will inhibit the visible growth of a microorganism.

\subsection{Statistical analyses}

All data were subjected to statistical analysis including the calculation of mean and stander error of the mean. Significance between data of groups was evaluated by student test at level $p<0.05$ using SPSS (statistical package for social science) version 10 computer programmer.

\section{Results}

Table 1 Effect of C12 (short and medium fatty acid) on different on chicken first sample

\begin{tabular}{lll}
\hline Parameters \& Groups & Control group & Treated group \\
\hline AST(U/L) & $132.2 \pm 4.46 \mathrm{a}$ & $122.8 \pm 2.24 \mathrm{~b}$ \\
ALT(U/L) & $38.9 \pm 2.87 \mathrm{a}$ & $32.6 \pm 2.54 \mathrm{~b}$ \\
Glucose(mg/dl) & $122.51 \pm 4.23 \mathrm{a}$ & $101.44 \pm 3.14 \mathrm{~b}$ \\
HDL(mg/dl) & $3.26 \pm 0.19 \mathrm{c}$ & $3.98 \pm 0.23 \mathrm{~b}$ \\
LDL(mg/dl) & $32.04 \pm 0.43 \mathrm{a}$ & $18.77 \pm 1.93 \mathrm{~b}$ \\
Cholesterol(mg/dl) & $48.71 \pm 1.53 \mathrm{a}$ & $37.53 \pm 2.54 \mathrm{~b}$ \\
Triacylglycerol(mg/dl) & $72.57 \pm 2.08 \mathrm{a}$ & $57.09 \pm 2.22 \mathrm{~b}$ \\
Total protein(g/dl) & $3.95 \pm 0.33 \mathrm{c}$ & $4.02 \pm 0.24 \mathrm{~b}$ \\
IL-6 (Pg./ml) & $9.82 \pm 0.29$ & $8.14 \pm 0.41 \mathrm{~b}$
\end{tabular}

Data are represented as (mean \pm S.E). S.E $=$ Standard error. Mean values with different superscript letters in the in the same columns are significantly different at $(\mathrm{p}<0.05)$. 
Abdel Maksoud et al. / GSC Advanced Research and Reviews, 2019, 01(01), 010-016

Table 2 Effect of C12 (short and medium fatty acid) on different on chicken second sample after 22 days.

\begin{tabular}{lll}
\hline Parameters \& Groups & Control group & Treated group \\
\hline AST(U/L) & $136.2 \pm 3.27 \mathrm{a}$ & $117.3 \pm 4.88 \mathrm{~b}$ \\
ALT(U/L) & $36.4 \pm 2.24 \mathrm{a}$ & $28.6 \pm 1.72 \mathrm{~b}$ \\
Glucose(mg/dl) & $135.15 \pm 4.41 \mathrm{a}$ & $111.79 \pm 5.73 \mathrm{~b}$ \\
HDL(mg/dl) & $3.22 \pm 0.13$ & $3.65 \pm 0.21 \mathrm{~b}$ \\
LDL(mg/dl) & $39.71 \pm 2.40 \mathrm{a}$ & $19.96 \pm 1.34 \mathrm{~b}$ \\
Cholesterol(mg/dl) & $60.01 \pm 2.34 \mathrm{a}$ & $42.51 \pm 1.70 \mathrm{~b}$ \\
Triacylglycerol(mg/dl) & $68.08 \pm 3.65 \mathrm{a}$ & $53.23 \pm 1.70 \mathrm{~b}$ \\
Total protein(g/dl) & $3.62 \pm 0.21 \mathrm{c}$ & $4.47 \pm 0.32 \mathrm{~b}$ \\
IL-6 (Pg/ml) & $10.81 \pm 0.36 \mathrm{a}$ & $7.16 \pm 0.49 \mathrm{~b}$ \\
\hline are represented as (mean \pm S.E). S.E= Standard error. Mean values with different superscript letters in the in the same columns are
\end{tabular}

Table 3 Effect of C12 (short and medium fatty acid) on different on chicken third sample after 33 day

\begin{tabular}{lll}
\hline Parameters \& Groups & control group & Treated group \\
\hline AST(U/L) & $150.6 \pm 4.69 \mathrm{a}$ & $119.3 \pm 3.27 \mathrm{~b}$ \\
ALT(U/L) & $42.2 \pm 2.28 \mathrm{a}$ & $29.9 \pm 1.54 \mathrm{~b}$ \\
Glucose(mg/dl) & $139.04 \pm 2.84 \mathrm{a}$ & $113.99 \pm 3.22 \mathrm{~b}$ \\
HDL(mg/dl) & $2.88 \pm 0.10 \mathrm{c}$ & $3.78 \pm 0.11 \mathrm{~b}$ \\
LDL(mg/dl) & $41.37 \pm 1.77 \mathrm{a}$ & $24.56 \pm 1.86 \mathrm{~b}$ \\
Cholesterol(mg/dl) & $62.28 \pm 2.81 \mathrm{a}$ & $40.96 \pm 2.32 \mathrm{~b}$ \\
Triacylglycerol(mg/dl) & $65.93 \pm 3.06 \mathrm{a}$ & $54.84 \pm 1.87 \mathrm{~b}$ \\
Total protein(g/dl) & $3.91 \pm 0.25 \mathrm{c}$ & $4.39 \pm 0.22 \mathrm{~b}$ \\
IL-6 (Pg/ml) & $14.04 \pm 0.46 \mathrm{a}$ & $8.06 \pm 0.52 \mathrm{~b}$ \\
\hline
\end{tabular}

Data are represented as (mean \pm S.E). S.E $=$ Standard error. Mean values with different superscript letters in the in the same columns are significantly different at $(\mathrm{p}<0.05)$.

Table 4 Effect of C12 (short and medium fatty acid) on body weights

\begin{tabular}{|c|c|c|c|c|c|c|}
\hline \multirow[t]{2}{*}{ Samples } & \multirow{2}{*}{$\begin{array}{l}\text { Volume } \\
(\mu)\end{array}$} & \multicolumn{2}{|c|}{ Gram + ve } & \multicolumn{2}{|l|}{ Gram -ve } & \multirow{2}{*}{$\begin{array}{l}\text { Fungi } \\
\text { Aspergillus niger }\end{array}$} \\
\hline & & $\begin{array}{l}\text { Bacillus } \\
\text { ceruse }\end{array}$ & $\begin{array}{l}\text { Staphylococcus } \\
\text { aureus }\end{array}$ & $\begin{array}{l}\text { Pseudomonas } \\
\text { aeruginosa }\end{array}$ & $\begin{array}{l}\text { Escherichia } \\
\text { coli }\end{array}$ & \\
\hline C12 & 100 & 43 & 40 & 35 & 37 & 41 \\
\hline \multicolumn{7}{|c|}{ Size of well $9 \mathrm{~mm}$} \\
\hline
\end{tabular}



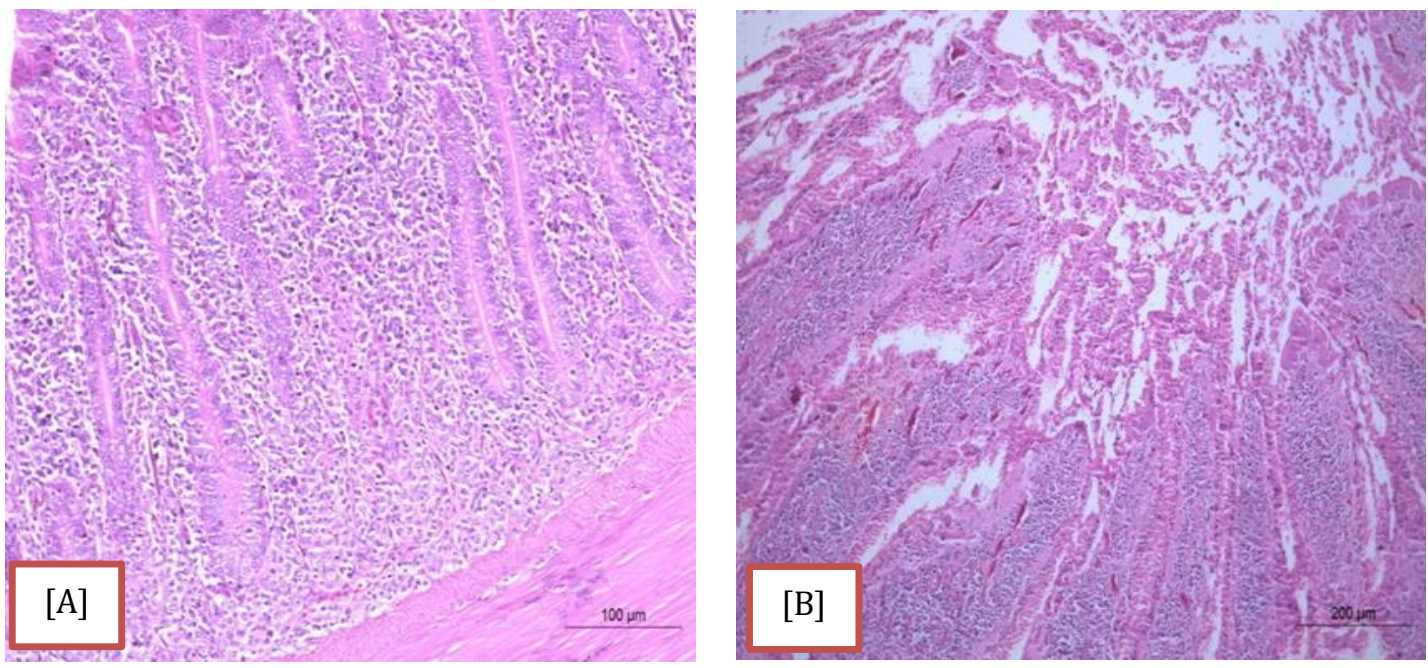

Figure 1 [A and B] Photomicrograph of intestine After 20 days, the examined intestine show catarrhal enteritis which is characterized by excess mucus production and increased secretions of enterocytes that cause accumulation of fluid in the intestinal lumen. Necrosis of enterocytes may be scattered along the surface of villi. Lymphocytes, along with massive numbers of granular leukocytes, often expand the lamina propria. Edema may also contribute to expansion of the lamina propria. Loss of mature enterocytes at the tips and sides of the upper portions of villi leads to hyperplasia of crypt epithelium because of the need to produce new cells to replace lost mature enterocytes. Villus length is decreased when mature enterocyte loss exceeds replacement of enterocytes generated in the crypts. The presence of focal to diffuse hemorrhage in the lamina propria may be evident.
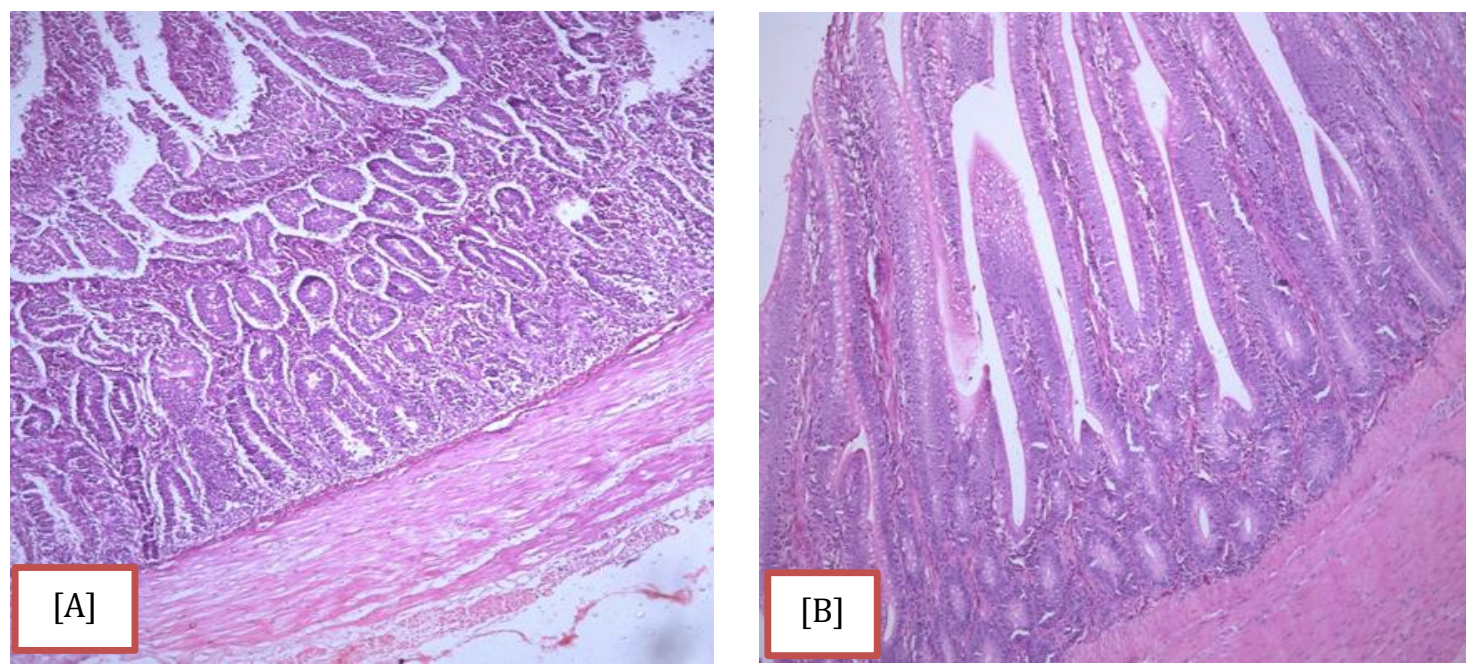

Figure 2 [A and B] Photomicrograph of intestine of broiler chick showing elongation of intestinal villi and villi show active goblet cell after adding C12 (short and medium fatty acid chain) The histopathological changes were moderate activation of enterocytes, increasing of villi length and slight increase in mononuclear cells in the lamina propria.

\section{Discussion}

The obtained data demonstrated in table 1 revealed that, a significant decrease in ALT, AST, urea, creatinin, LDL, triglyceride, IL-6 and increase in HDL. These results come in accordance with [21] showed reduced levels of serum total and LDL cholesterol.

It is well known that (Short and medium chain fatty acid) improve gut health, by promoting the growth of beneficial bacteria while inhibiting the pathogenic bacteria. Beneficial bacteria like Lactobacillus sp. have high bile salt hydrolytic activity which is responsible for deconjugation of bile salts [22]. Deconjugated bile acids are less soluble, hence less absorbed in the intestine and are more likely to excrete cholesterol and its fraction in feces [23] thus reduction of cholesterol accretion in the body. 
Opposing to the effect of (short and medium fatty acid) on blood parameter. Supplementation of organic acids showed no significant $(\mathrm{P}>.05)$ difference in the concentration of serum glucose and cholesterol among all the treatment groups including the control group confirming the earlier findings that organic acid supplementation had no effect on the blood metabolites in the broiler chicken [24].

Supplementation of organic acids showed no significant $(P>.05)$ difference in the concentration of serum glucose and cholesterol among all the treatment groups including.

\section{Conclusion}

Based on the results in the current research, supplementing (short and medium fatty acid) had positive outcome on the performance, because of their beneficial antimicrobial effect apart from positive impact on histology of the small intestines, thereby facilitating the nutrient absorption and growth performance in broiler chicken. Improving the lipid metabolism, and immune status of bird.

\section{Compliance with ethical standards}

\section{Disclosure of conflict of interest}

The authors declare that they have no conflict of interest

\section{Statement of ethical approval}

The study protocol was approved by the institutional ethics committee.

\section{References}

[1] Van Der Wielen PW, Biesterveld S, Notermans S, Hofstra H, Urlings BA and Van Knapen F. (2000). Role of volatile fatty acids in development of the cecal microflora in broiler chickens during growth. Applied and Environmental Microbiology, 66 (6), 2536-40.

[2] Adil S, Banday T, Bhat GA, Mir MS and Rehman M. (2010). Effect of dietary supplementation of organic acids on performance, intestinal histomorphology, and serum biochemistry of broiler chicken.

[3] Saki AA, Harcini RN, Rahmatnejad E and Salary J. (2012). Herbal additives and organic acids as antibiotic alternatives in broiler chickens diet for organic production. Afr. J. Biotechnol, 11, 2139-2145.

[4] Windisch W, Schedle K, Plitzner C and Kroismayr A. (2008). Use of phytogenic products as feed additives for swine and poultry. Journal of Animal Science, 86, 140-148.

[5] Van Immerseel F, J De Buck, I De Smet, F Pasmans, F Haesebrouck and en R Ducatelle. (2004). Interactions of butyric acid and acetic acid treated salmonella with chicken primary cecal epithelial cells in vitro. Avian Dis. 48, 384-391.

[6] Humphrey TJ and Lanning DG. (1988). The vertical transmission of salmonellas and formic acid treatment of chicken feed: A possible strategy for control. Epidemiology and Infection, 100, 43-49.

[7] Kwan YM and Ricke SC. (2005). Induction of acid resistance of Salmonella typhimurium by exposure to short chain fatty acids. Appl. Environ. Microbiol, 64(9), 3458 - 3463.

[8] Odle J. (1997). New insights into the utilization of medium-chain triglycerides by the neonate: Observations from a piglet model. J Nutr, 127, 1061-7.

[9] Jacobi SK and Odle. (2012). Effect of dietary supplementation of organic acids on performance and serum biochemistry of broiler chicken. Natur. Sci, 12(2), 38-45.

[10] Rossi R, Pastorelli G, Cannata S and Corino C. (2010). Recent advances in the use of fatty acids as supplements in pig diets: a review. Anim Feed Sci Technol, 162, 1-11.

[11] Dierick N, Decuypere J, Molly K, Van Beek E and Vanderbeke E. (2003). The combined use of triacylglycerol containing medium-chain fatty acids (MCFAs) and exogenous lipolytic enzymes as an alternative for nutritional antibiotics in piglet nutrition. Nutrition Research Reviews, 16, 193-209. 
[12] Huyghebaert G, Ducatelle R and Immerseel FV. (2011). An update on alternatives to antimicrobial growth promoters for broilers. Vet. J, 187, 182-188.

[13] Sato H, Nitana A, Kurosawa T and Oikawa S. (2004). Anticoccidial efficacy of medium-chain triglycerides (MCT) in calves J Vet Med Sci, 66(12), 1583-1585.

[14] Murray. (1984). Report on the symposium "drug effect in clinical chemistry methods for Estimation of ALT. Eur] Clin Chem clin Biochem., 34, 1088-1090.

[15] Burtis A, Carl A, Edward R and Ashwood MD. (1999). Tietz Textbook of clinical chemistry 3rd Edition.

[16] Schettler G and Nussel E. (1975). Colorimetric determination of Total cholesterol, Triglycerides. Arb. Med. Soz. Med. Prav. Med., 10, 25.

[17] Gordon T. (1977). Colorimetric determination of serum HDL cholesterol. Amer. J.Med, 62, 707.

[18] Friedewald WT. (1972). Colorimetric determination of serum LDL cholesterol,Clin. Chem., (18), 499.

[19] Caraway WT and Watts NB. (1987). 3rd ed. Philadephia WB sande-rs, 422-447.

[20] Bancroft JD and Stevens A. (1996). Theory and practice of histological technique.4th edition. Churchill, Livingston, New York, London, San Francisco, Tokyo.

[21] Deepa K, Purushothaman MR, Vasanthakumar P and Sivakumar K. (2017). Serum Biochemical Parameters and Meat Quality Influenced Due to Supplementation of Sodium Butyrate in Broiler Chicken. Int. J. Livestock Res., $7(8), 108-116$.

[22] Sarono S. (2003). In vitro probiotic properties of indigenous dadih lactic acid bacteria.Asian- Australian J. Ani. Sci., 16(5), 726-731.

[23] Klaver FA and R Van der Meer. (1993). The assumed assimilation of cholesterol by Lactobacillus and Bifidobac0terium bifidum is due to their bile salt deconjugating activity. Appl. Enviro. Microbio, l. 59(4), 11201124.

[24] Sheikh A, Tufail B, Gulam AB, Masood SM and Manzoor R. (2010). Effect of dietary supplementation of organic acid on performance, intestinal histomorphology, and serum biochemistry of broiler chicken. Vet Med Int, 479485.

\section{How to cite this article}

Abdel Maksoud H Mahfouz KM, Afaf Abd ED, Yomna H. and Ahmed F. (2019). Biochemical evaluation of antibacterial activity of short and medium chain fatty acids in broiler. GSC Advanced Research and Reviews, 1(1), 10-16. 